\title{
Experiment and Simulation of Earthen Embankment Breach
}

\author{
Sanit Wongsa \\ Department of Civil Technology Education, King Mongkut's University of Technology Thonburi (KMUTT), \\ Bangkok, Thailand \\ Email: sanit.won@kmutt.ac.th
}

Received November 2015

\begin{abstract}
Many studies of earthen embankment failure from overtopping flow have been conducted in various aspects. Most of them focused on the mechanism of breach, depth and width of erosion, and breach hydrograph. The results were obtained either from both physical and numerical modeling and/or coupling techniques. However, a physical hydraulic model of the effect of breach mechanism under three types; overtopping, beneath structure and piping hole have not been studied. Fixed embankment slopes with scale of 1:8.5 were employed to perform the experiment. It was found that the piping hole case at the toe of embankment was the most severe damage. The iRIC Nays2D numerical model shows a good performance of simulated results in both water flow and breach morphological characteristics, indicating that the model simulation is reasonable.
\end{abstract}

\section{Keywords}

Embankment Breach, Characteristics of Failure, Overtopping, Beneath Structure, Piping Hole

\section{Introduction}

Earthen embankments, including dikes and dams, are of large benefit to people all over the world. Most of the earthen embankments were built up of cohesive soil and/or impervious soil. In the case of flood protection, permanent or temporality embankments were often used for protecting restricted area from a flood water level of some magnitude. However, as flood disaster is a natural phenomenon which is unpredictable, sometime, the flood level might be higher than the embankment height and overtopping flow would then occur. However, embankments could also give human lives and properties high risks to some extend for their failures due to overtopping, piping and other factors. The result of overtopping flow is the erosion on the embankment surface and the scour at the toe. No matter how the embankment was compacted well at the construction phase, gradual decreases in its strength due to weathering effects and negligence of proper maintenance and increase in soil moisture during flood event were unavoidable. These two effects became the prominent causes of the embankment failure.

Physical model is a useful and popular tool to investigate the breaching process in the embankment and has been applied by the former researchers [1] [2] in the laboratory. However, the scale limitations increase the uncertainty of the breaching development and the result distortions have been generated. In the meantime, re- 
searchers use prototype data analyses and conduct the real embankment breach tests in the field to get insights into the mechanism of breach development. But the data collected from prototype are usually not complete.

Severity of the embankment breach depended also on the overtopping flow discharge. In the study of cohesive embankment breach by many researchers [3]-[5], it was indicated that breach mechanism consists of 2 processes, the surface erosion and the head cut erosion. The width of the breach was assumed to be dynamically controlled by two parameters; the critical depth at the entrance to the breach channel and the stability slope of the embankment materials. The breach width, as expanding on both sides, would form a trapezoidal section. This concept of breach channel development has been adopted for formulating most of numerical models available presently, even though inconsistency with real events when applied to the cases where breach location occurred near uneroded wall of a hydraulic structure. Examples of such embankment breach included the failure Bang Chom Sri regulator in Thailand [6]. There were many comparative studies on the embankment failure which occurred in laboratory and real embankment scale breach by numerical model [7] [8]. It was found that under the same overtopping flow conditions, the embankment erosion which occurred near the regulator was compared well. Hence, it is the purpose of this study to investigate the embankment breaching under three different conditions (overtopping, beneath structure, and piping hole). The results might be used for developing guidelines to protect hydraulic structures from failures caused by embankment breaching and flood. The observed data can also be analyzed to apply for the development and validation of a numerical model to simulate the embankment breaching process.

\section{Materials and Methods}

\subsection{Experiment Setup}

The re-circulating flow basin, as shown in Figure 1, 3 types of experiments, (overtopping, beneath structure and piping hole)were conducted in the flume of $15.50 \mathrm{~m} \times 1.50 \mathrm{~m} \times 1.50 \mathrm{~m}$ of King Mongkut's University of Technology Thonburi (KMUTT), Thailand. The discharge that can be supplied at 4 constant discharges, 4.14, 7.78, 11.59 and $16.48 \mathrm{l} / \mathrm{s}$, and flow discharge was controlled by using 4 pumps. Two sidewall of the flume were made up of concrete block, and the transit zone was built with gravel and measured flow discharge by V-notch weir.

The embankments were built on non-erodible flume bed, $0.48 \mathrm{~m}$ thick of soil mixture (SW-SC). In order to know the material properties, several standard geotechnical tests were performed on the soils and on the mixtures (Table 1), with the average grain size and density of $1.70 \mathrm{~mm}$, and $14.70 \mathrm{kN} / \mathrm{m}^{3}$, respectively. Before starting each experiment, the earthen embankment had been soaked for 2 hours. The surface erosion began immediately after the embankment overtopped. The breaching process was recorded by two video cameras.

\section{2. iRIC Model}

The iRIC Nay2D model was used for simulation of earthen embankment breach and its morphology. Water flow and morpho dynamics of earthen embankment breach were calculated by the shallow water equation of twodimensional unsteady flow and sediment transport [9].

Table 1. Properties of soil mixture used for the experiments.

\begin{tabular}{|c|c|c|c|}
\hline \multicolumn{4}{|c|}{ Soil Properties } \\
\hline Items & Values & Items & Values \\
\hline Specific Gravity, Gs & 2.87 & Friction Angle, $\phi$ & 17 \\
\hline Liquid Limit, LL\% & 51 & Cohesion, $C$ & 17 \\
\hline Plastic Limit, PL\% & 24 & Total Weight of Soil & 14.7 \\
\hline Plastic Index, PI & 27 & Initial Void Ratio & 0.89 \\
\hline Cc & 29.7 & Initial Coeff. of Permeability & $5.1 \times 10^{-6}$ \\
\hline $\mathrm{Cu}$ & 2.6 & Туре & SW-SC \\
\hline
\end{tabular}



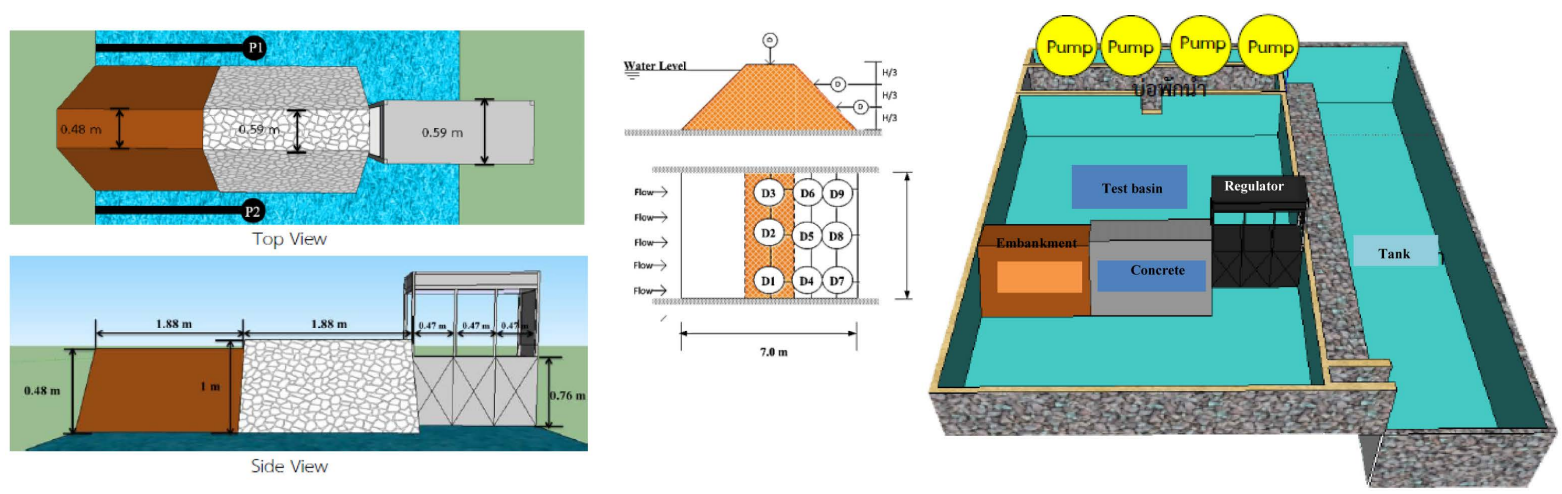

Figure 1. Experiments setup flume, embankment and instruments.

\section{Results and Discussion}

\subsection{Overtopping Case}

The first surface erosion started to form a few minutes after the initial overtopping of the embankment. Almost simultaneously another larger head cut started to form at approximately mid-height of the embankment slope. The surface erosion characteristics observed in this case were more of detachment of lumped material than of individual particle detachment. This head cut was wider than the one at the toe and deepened vertically. Other smaller head cuts were also observed. As time progressed, predominant water path in the middle of the embankment was observed. The development of breach depth is presented in Figure 2 and Figure 3. The embankment breach cross-section may be an approximate trapezoid. The data resembles an exponential curve. Once it reached the lower elevation, the breach widened and the material was eroded from the sides and from the upstream side. The breach remained stable after 130 minutes, the maximum breach depth and width were 0.26 and $1.12 \mathrm{~m}$, respectively. Most of the time the flow remained attached to the head cut wall, except when mass erosion of the vertical wall became imminent. Figure 4 shows the time series of embankment erosion width, depth, and volume of soil. The water in the testing channel was gradually drained out through the circulated channel until it was dry. The breached channel dimensions and the scour and deposition profile on the embankment foundation on the downstream side were measured in details.

\subsection{Beneath Structure Case}

After the embankment was soaked for 2 hours, the first erosion started to form a few minutes after the initial overtopping at the breach portion beneath embankment-structure due to a weakness at junctional between soil and concrete and/or structural joints. This breach portion was deeper than the overtopping case and deepened vertically. Other breach portion was not observed because the water level dropped at the upstream. As time progressed, predominant water path in the side of the embankment-structure was observed. The development of breach depth is presented in Figure 5 and Figure 6. The embankment breach cross-section might be an approximate rectangular. Once it reached the lower elevation, the breach widened and the material was eroded from the sides and from the upstream side. The breach remained stable after 120 minutes, the maximum breach depth and width were 0.36 and $0.57 \mathrm{~m}$, respectively. Most of the time the flow remained attached to the head cut wall, except when mass erosion of the vertical wall became imminent. Figure 7 shows the time series of embankment erosion width, depth, and volume of soil. The water in the testing channel was gradually drained out through the circulated channel until it was dry. The breached sediment deposition with a fan shaped was observed.

\subsection{Piping Hole Case}

Piping and liquefaction may occur because of the seepage or leakage flow through weak layers, structural joints, dead tree roots, and animal burrows in the embankment without the necessity of the water level reaching the full height of the embankment. As time progressed, predominant water path in the middle of the embankment was observed. The piping hole became widen faster than previous cases and the advance process took faster to reach 

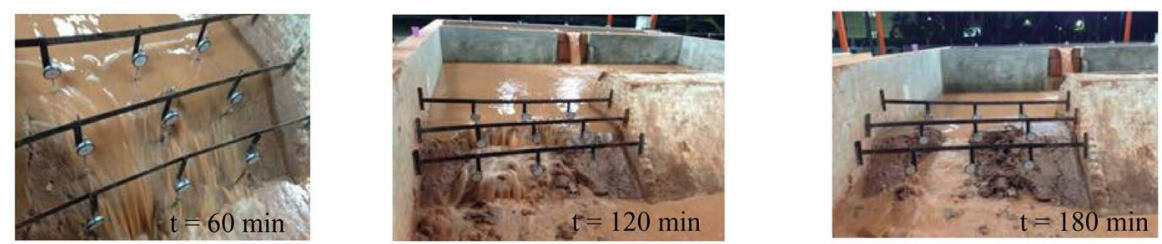

Figure 2. The failure characteristics of the earthen embankment; overtopping case (at $\mathrm{Q}=16.84 \mathrm{l} / \mathrm{s}$ ).

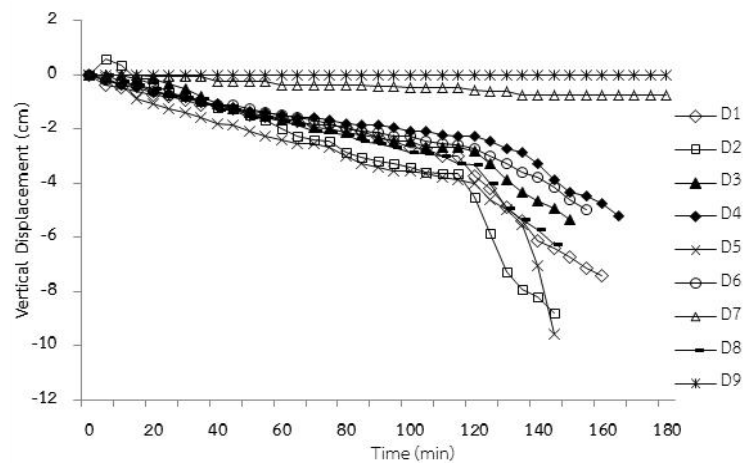

(a)



(c)

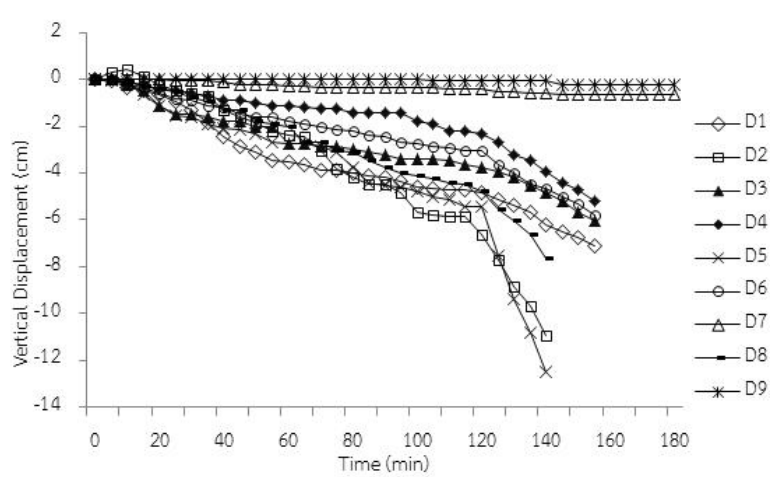

(b)

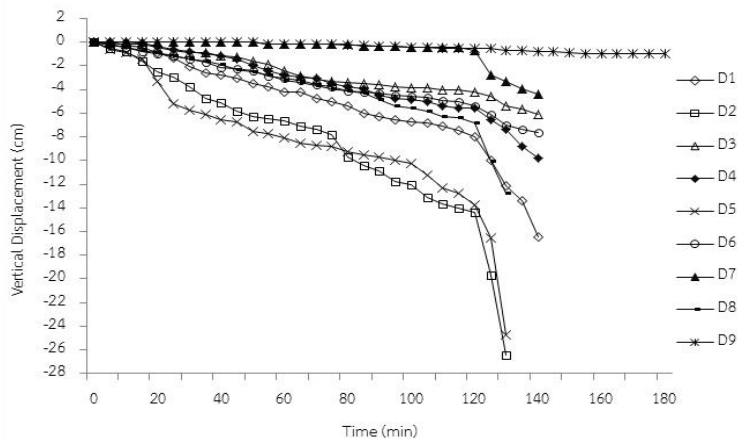

$(\mathrm{d}$

Figure 3. The vertical displacement of embankment; overtopping case. (a) $Q=4.14$ l/s; (b) $Q=7.78$ l/s; (c) $Q=11.59$ l/s; (d) Q $=16.84 \mathrm{l} / \mathrm{s}$.


Figure 4. Time series of embankment erosion width, depth, and volume of soil of overtopping case.

the embankment crest. The lumped material simultaneously dropped, another larger head cut started to form at approximately mid-height of the embankment slope. The surface erosion characteristics were observed in this case. The development of breach depth is presented in Figures 8-10. The breach remained stable after $130 \mathrm{mi}-$ nutes, the maximum breach depth and width were 1.34 and $0.26 \mathrm{~m}$. Excessive foundation seepage through permeable substrata is often accompanied by the formation of sand boils, which often look like miniature volcanoes ejecting water and sediment, and may result in piping failure if not controlled. High uplift pressure and saturation of foundation materials may give rise to slope instability and sliding failure. The piping failures caused by 

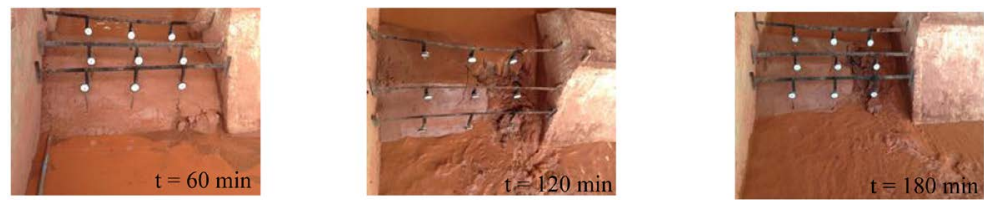

Figure 5. The failure characteristics of the earthen embankment; beneath structure case (at $\mathrm{Q}=16.84 \mathrm{l} / \mathrm{s}$ ).

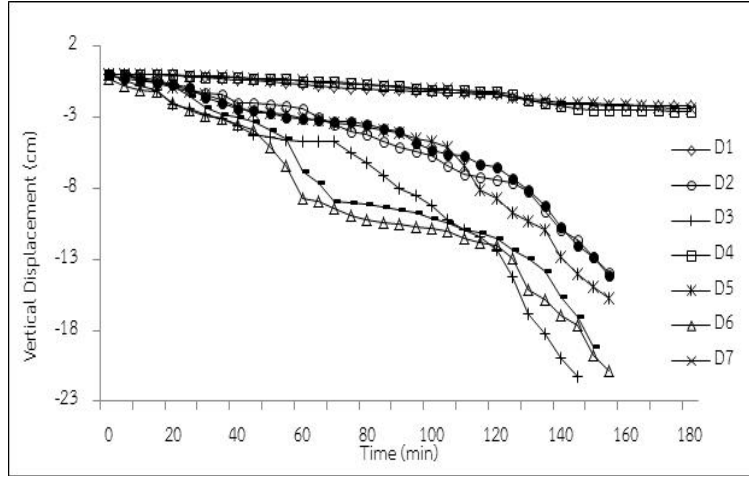

(a)

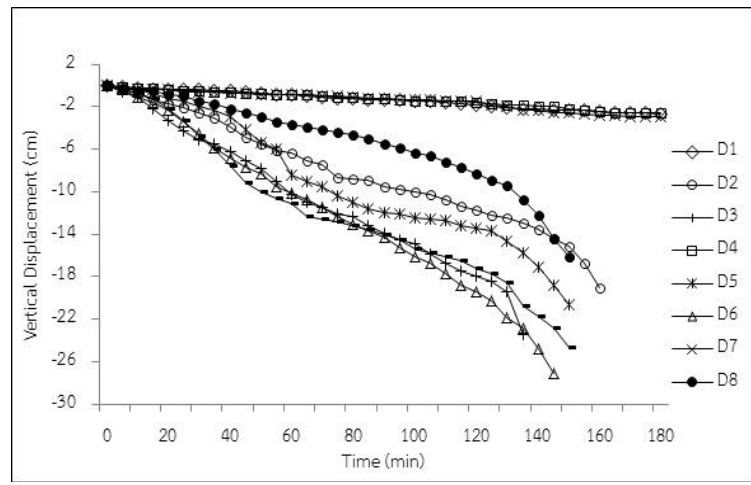

(c)



(b)

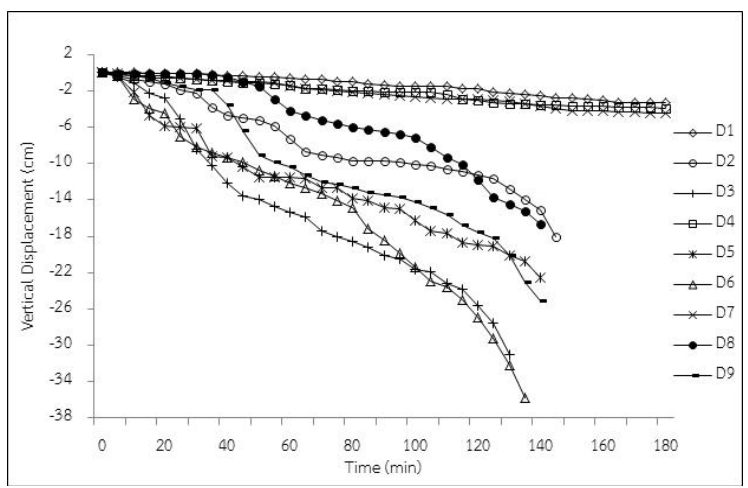

(d)

Figure 6. The vertical displacement of embankment; beneath structure case. (a) $Q=4.14$ l/s; (b) $Q=7.78$ l/s; (c) $Q=11.59$ $\mathrm{l} / \mathrm{s}$; (d) $\mathrm{Q}=16.84 \mathrm{l} / \mathrm{s}$.
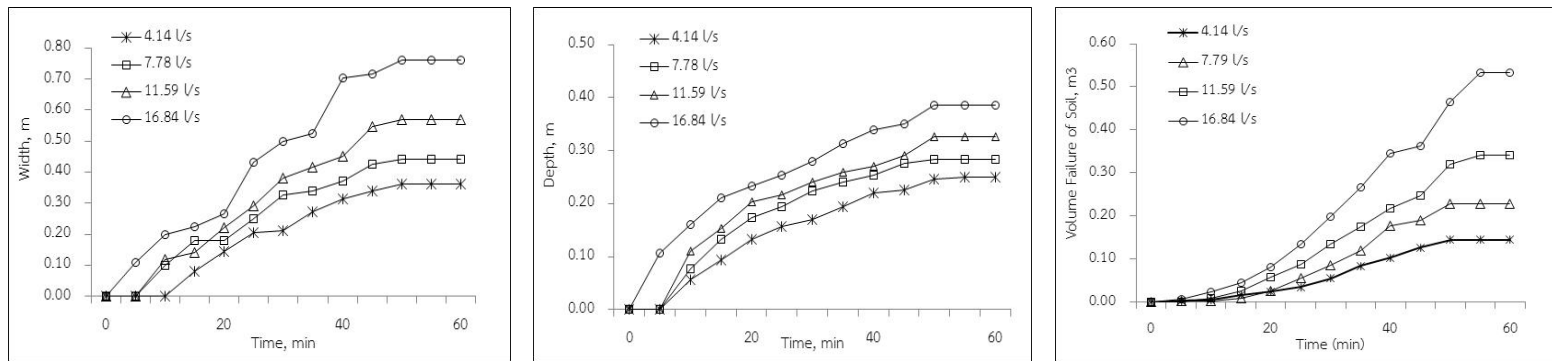

Figure 7. Time series of embankment erosion width, depth, and volume of soil of; beneath structure case.

foundation defects are similar to those described in the preceding subsection, but the initial breaches may involve the whole height of the embankment. Sliding failures can form a large rupture much more rapidly than piping failures.

\subsection{Model Simulation}

The comparison of time series of breach width and depth between experiment measured data and simulated of 

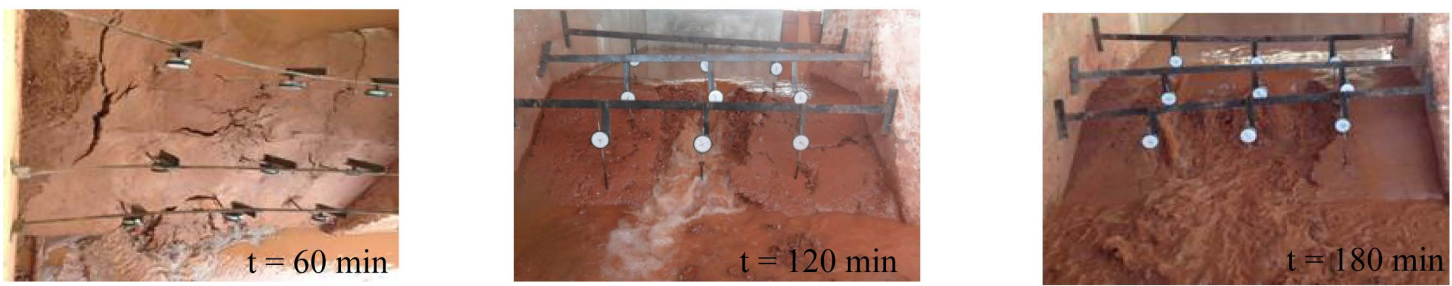

Figure 8. The failure characteristics of the earthen embankment; piping hole case (at $\mathrm{Q}=16.84 \mathrm{l} / \mathrm{s}$ ).

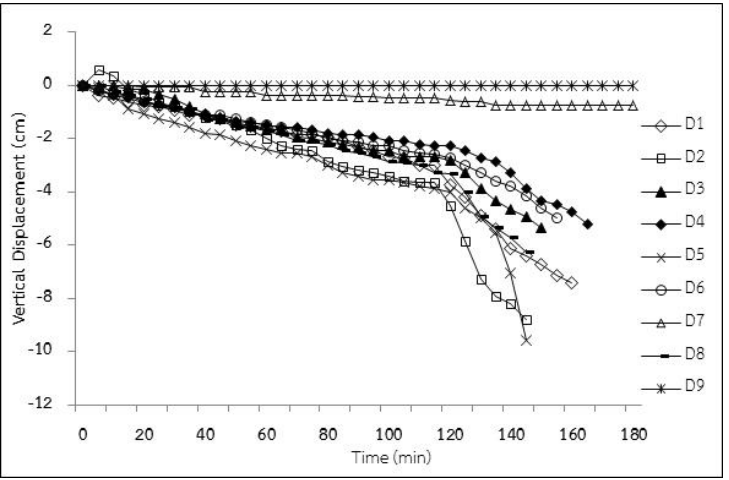

(a)

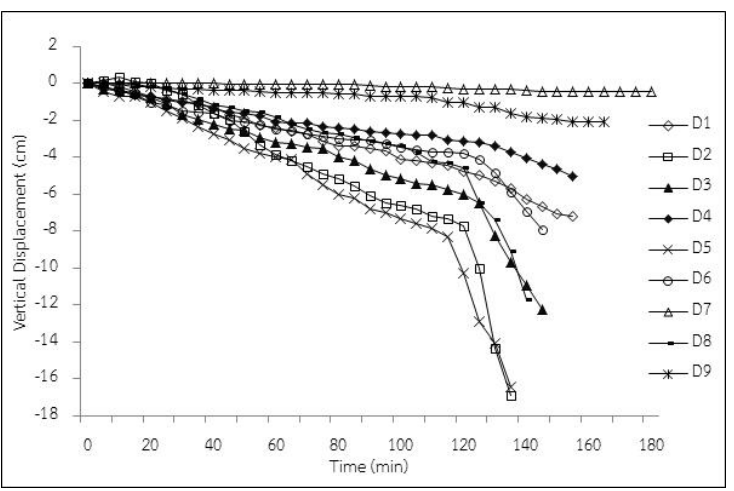

(c)

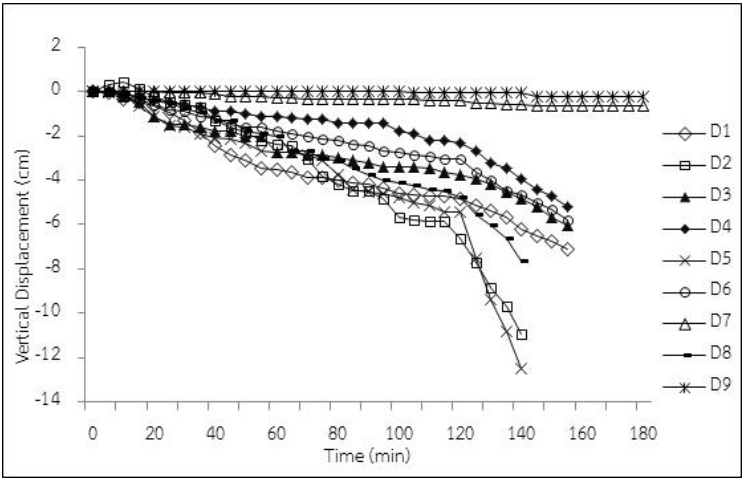

(b)

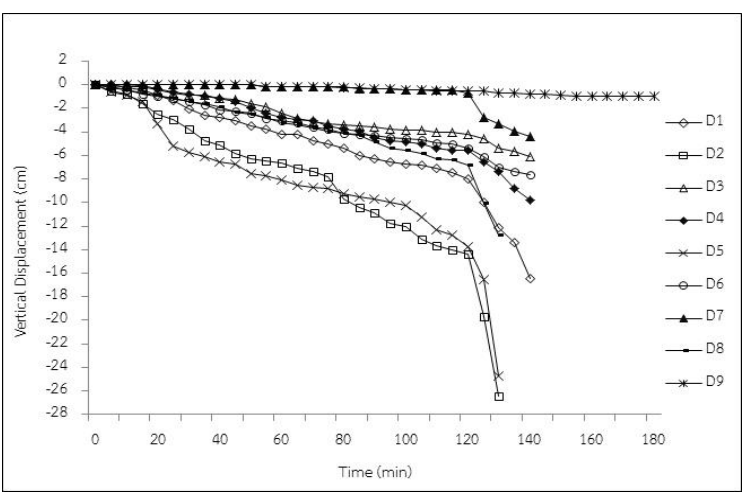

(d)

Figure 9. The vertical displacement of embankment; piping hole case. (a) Q = 4.14 l/s; (b) Q = 7.78 l/s; (c) Q = 11.59 l/s; (d) $\mathrm{Q}=16.84 \mathrm{l} / \mathrm{s}$.
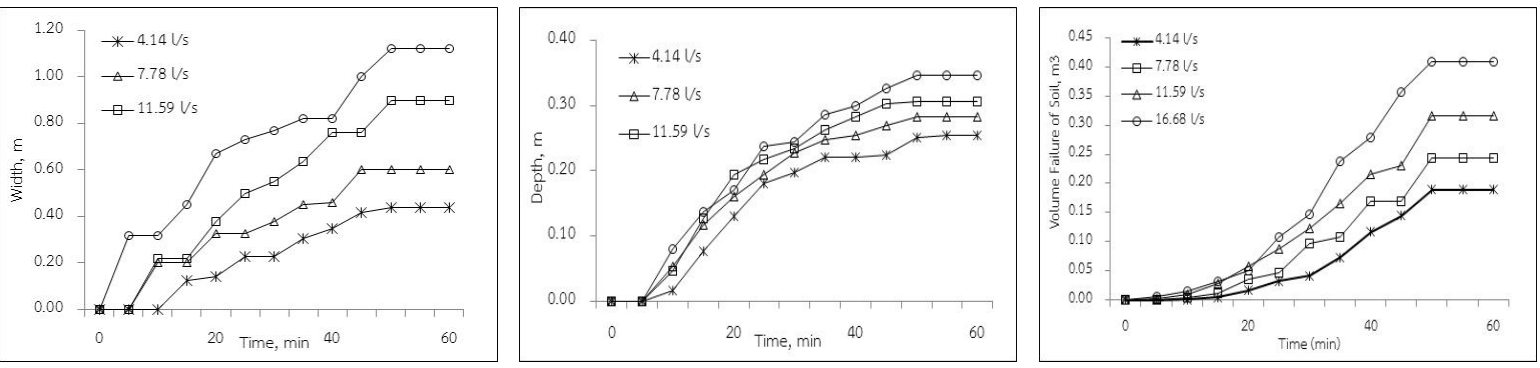

Figure 10. Time series of embankment erosion width, depth, and volume of soil; piping hole case.

results from iRIC Nay2D model are show in Figure 11. These results indicate well agreed between experimental data and this proposed model. Good performance of simulated results were observed in both water flow (flow field, flow vector) and breach morphological characteristics (breaching position, width, depth), indicating that model simulation is reasonable. 

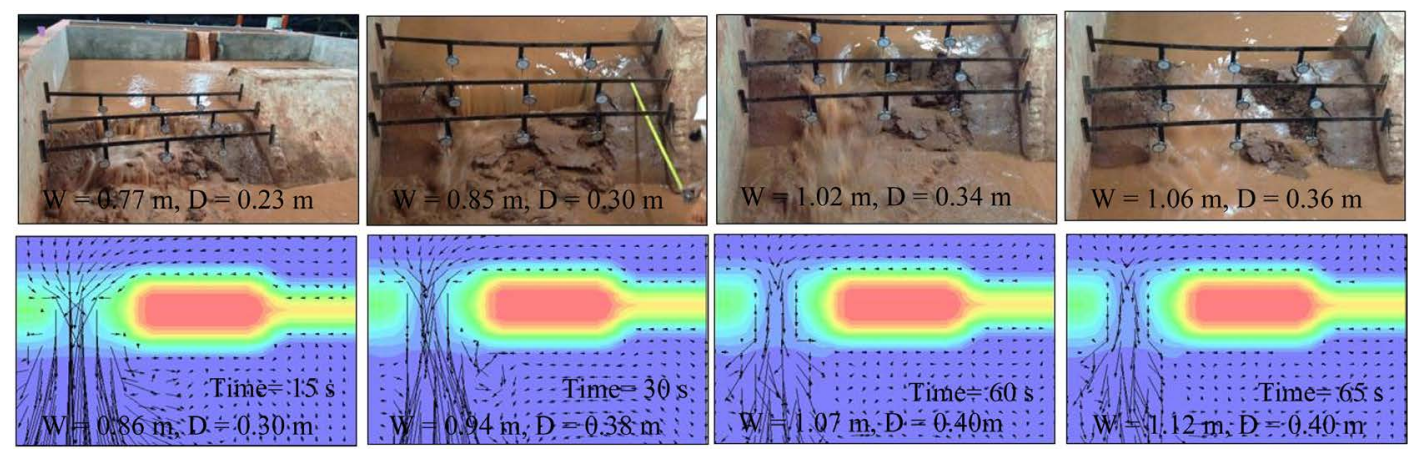

Figure 11. Time series of embankment erosion width, depth, and volume of soil; overtopping case.

\section{Conclusion}

The embankment breach and failure characteristic were studied by using physical and numerical simulation, under 3 types of experiments (overtopping, beneath structure and piping hole). The discharge that can be supplied at 4 constant discharges which were4.14, 7.78, 11.59 and $16.48 \mathrm{l} / \mathrm{s}$. The results indicate that the breach types have an effect on the maximum breach width, depth and volume of eroded soil. The piping hole at the toe of embankment was the most severe damage. The iRIC Nays2D numerical model shows a good performance of simulated results in both water flow and breach morphological characteristics, therefore, indicating that the model simulation is reasonable. The results can be used for developing the guidelines to protect hydraulic structures from failures caused by embankment breaching, and flood. However, it is important to conduct larger scale laboratory experiments and field case studies to improve existing embankment breach models or develop the new ones.

\section{Acknowledgements}

The authors would like to thank NRU—National Research University, Hydro and Agro Informatics Institute (HAII) and King Mongkut's University of Technology Thonburi (KMUTT) for financial support in this study. I am also thankful to master and graduated students who involved in the experiments.

\section{References}

[1] Visser, P.J. (1998) Breach Growth in Sand-Dikes. PhD Thesis, Delft University of Technology, Delft, The Netherlands.

[2] Zhu, Y.H. (2006) Breach Growth in Clay-Dikes. PhD Thesis, Delft University of Technology, Delft, The Netherlands.

[3] Stein, O.R. and Julien, P.Y. (1993) Criterion Delineating the Mode of Headcut Migration. Journal of Hydraulic Engineering, 119, 37-50. http://dx.doi.org/10.1061/(ASCE)0733-9429(1993)119:1(37)

[4] Hahn, W., Hanson, G. and Cook, K. (2000) Breach Morphology Observations of Embankment Overtopping Tests. Joint Conference on Water Resource Engineering and Water Resources Planning and Management, Building Partnerships, 1-10. http://dx.doi.org/10.1061/40517(2000)411

[5] Zhang, J., Li, Y., Xuan, G., Wang, X. and Li, J. (2009) Overtopping Breaching of Cohesive Homogeneous Earth Dam with Different Cohesive Strength. Science in China Series E: Technological Sciences, 52, 3024-3029. http://dx.doi.org/10.1007/s11431-009-0275-1

[6] Wongsa, S. (2014) Simulation of Thailand Flood 2011. IACSIT International Journal of Engineering and Technology, 6, 452-458. http://dx.doi.org/10.7763/IJET.2014.V6.740

[7] Tamoon, R. and Wongsa, S. (2015) The Study of Behavior of Failure Earthen Dike Due to Flow Overtopping. Proceedings of NCCE2011, Chonburi, Thailand.

[8] Yuangyai, C. and Wongsa, S. (2015) Simulation of Failure Earthen Dike by Using iRIC Nays2D Program Case Study: Bang Chom Sri Regulator. The Journal of Industrial Technology, 11.

[9] http://i-ric.org/en/introduction 